\title{
Superficial haemosiderosis of the central nervous
}

system

\author{
B. E. TOMLINSON AND JOHN N. WALTON \\ From the Departments of Neuropathology and Neurology, Regional Neurological Centre, the General Hospital, \\ Newcastle upon Tyne
}

In 1940 Noetzel reported two cases of slowly progressive neurological illness in which, at necropsy, the meninges overlying the brain and spinal cord and the peripheral areas of the brain, cerebellum, and spinal cord were found to be rust-brown in colour. Iron pigment was found in the meninges, glial cells, within mesodermal cells and around blood vessels in the cortex, and in the lining of the cerebral ventricles, and the pigmented cerebellar convolutions were disorganized. The author concluded that this condition was due to the diffusion of blood pigment into the marginal zone of the central nervous system and suggested that the condition was probably the result of chronic subarachnoid bleeding. Subsequently, however, additional cases were reported by Lewey and Govons (1942), Cammermeyer (1947), Neumann (1948, 1956), Garcin and Lapresle (1957), Rosenthal (1958), and McGee, van Patter, Morotta, and Olszewski (1962). Neumann $(1948,1956)$ concluded that the pathological changes in the central nervous system which she observed in her two cases were the result of haemochromatosis of the central nervous system. Others, however, have pointed out that the pigment deposits consist of haemosiderin and suggest that in most, if not all, cases this disorder results from repeated or long-continued bleeding into the subarachnoid space. In all, 11 cases of this type have now been reported in the world literature. They have shown a remarkably consistent clinical picture characterized particularly by progressive dementia, nerve deafness, and cerebellar ataxia, and the pathological changes in the reported cases have also been strikingly uniform in character. Table I summarizes details of the cases reported to date and we give below detailed clinical and pathological observations in the first case of this type to be reported from Great Britain.

\section{CASE REPORT}

CLINICAL DETAILS An untrained children's nurse, aged 16 years, was admitted to the Newcastle General Hospital for investigation on 13 May 1959. For two years she had $\frac{\overline{\bar{S}}}{\overline{\frac{1}{3}}}$ suffered from paroxysnal headaches with vomiting which ${ }_{\circ}^{\mathbb{D}}$ had become much more severe in the last six months. During the headache the patient would often experience ${ }^{\infty}$ blurring of vision and transient right-sided hemianopia. $\vec{O}$ Independently of these headaches she had begun to experience brief episodes lasting only a few seconds in $\vec{\omega}$ which she lost the power of speech and would go 'blank'? for a few seconds. Tongue-biting and incontinence had? never occurred. Recently too she had seemed to become slow and disinterested and intermittently drowsy and her $N$ appetite and weight had diminished considerably.

On examination on admission the patient was conscio $s_{\epsilon}^{\omega}$ and coherent but seemed dull, lethargic, and dis terested. She complained intermittently of right-sidg్d headache. The optic fundi were normal, but examinationof the visual fields revealed a congruous right upper quadrantic field defect. There were no other clear-catec neurological signs on examination. Survey views of the skull showed no significant bony abnormality; the pineal gland was faintly calcified but could not be accurat $\vec{\theta}$ identified in the antero-posterior view. A lumbar puncture was not performed. During her stay in hospital the patient was observed to have recurrent attacks of minoro epilepsy. An E.E.G. was abnormal; it showed generalized paroxysms of slow activity of both theta and delta fre-o quency suggestive of epilepsy of central origin. There was $\stackrel{2}{\mathscr{Q}}$ no clear evidence of a focal lesion in either cerebral $\stackrel{\AA}{\perp}$ hemisphere. Bilateral carotid arteriography was per- $\stackrel{\vec{z}}{\vec{p}}$ formed on 19 May. No angioma or other vascular mal-o formation and no pathological circulation was demonstrated in either hemisphere, but Dr. G. L. Gryspeerdt commented that the appearance suggested a degree of dilatation of both lateral ventricles.

The patient was treated with anticonvulsants and ergotamine preparations; the headaches improved and she became more alert; she was discharged home on 273 . May 1959. She was seen again on 11 July and had deteriorated. Her speech had become slurred and her gait $\frac{0}{3}$ unsteady, she was continuing to lose weight, and her 'blackouts' were more frequent. The patient was re-을 admitted to hospital on 14 July. She was found to be $>$ confused, disorientated, and lethargic and formal intellectual testing indicated a degree of early dementia. There was some neck stiffness and the visual field defect was $\sigma$ unchanged. Psychometric tests showed that she appeared N to be functioning at the 'high-grade feeble minded' level $N$ 
TABLE I

12 REPORTED CASES OF SUPERFICIAL HAEMOSIDEROSIS OF THE CENTRAL NERVOUS SYSTEM (INCLUDING PRESENT CASE)

\begin{tabular}{|c|c|c|c|c|c|c|c|c|c|}
\hline \multirow[t]{3}{*}{ or and } & \multirow{3}{*}{$\begin{array}{l}\text { Age and } \\
\text { Sex of } \\
\text { Patient }\end{array}$} & \multicolumn{6}{|c|}{ Clinical Features } & \multirow{2}{*}{\multicolumn{2}{|c|}{$\begin{array}{l}\text { Pathological Features } \\
\text { Other than Haemosiderosis }\end{array}$}} \\
\hline & & \multirow{2}{*}{$\begin{array}{l}\text { Duration } \\
\text { of Illness }\end{array}$} & \multirow{2}{*}{$\begin{array}{l}\text { Cerebellar } \\
\text { Ataxia }\end{array}$} & \multirow{2}{*}{$\begin{array}{l}\text { Nerve } \\
\text { Deafness }\end{array}$} & \multirow{2}{*}{ Dementia } & \multirow{2}{*}{$\begin{array}{l}\text { Sphincter } \\
\text { Dis- } \\
\text { turbance }\end{array}$} & \multirow[t]{2}{*}{ Spasticity } & & \\
\hline & & & & & & & & $\begin{array}{l}\text { Subarachnoid } \\
\text { Bleeding }\end{array}$ & Aetiology \\
\hline zel 1940 & M 47 & $\begin{array}{l}\text { Not } \\
\text { known }\end{array}$ & $\begin{array}{l}\text { Not } \\
\text { known }\end{array}$ & + & + & $\begin{array}{l}\text { Not } \\
\text { known }\end{array}$ & - & Xanthochromia & $\begin{array}{l}\text { Carcinomatosis of } \\
\text { meninges. } \\
\mathrm{Ca} \text { of stomach }\end{array}$ \\
\hline zel 1940 & F 59 & $\begin{array}{l}\text { Not } \\
\text { known }\end{array}$ & $\begin{array}{l}\text { Not } \\
\text { known }\end{array}$ & $\begin{array}{l}\text { Not } \\
\text { known }\end{array}$ & $\begin{array}{l}\text { Not } \\
\text { known }\end{array}$ & $\begin{array}{l}\text { Not } \\
\text { known }\end{array}$ & + & $\begin{array}{l}\text { Xanthochromia } \\
\text { ('Haemorrhagic } \\
\text { meningitis') }\end{array}$ & $\begin{array}{l}\text { Not found at } \\
\text { necropsy }\end{array}$ \\
\hline $\begin{array}{l}y \text { and } \\
\text { sns } 1942\end{array}$ & M 36 & 7 years & ++ & + & + & + & + & $\begin{array}{l}\text { Xanthochromia, } \\
\text { bleeding suspected }\end{array}$ & $\begin{array}{l}\text { Not found at } \\
\text { necropsy }\end{array}$ \\
\hline nann 1948 & M 47 & 12 years & ++ & + & + & + & + & + & $\begin{array}{l}\text { 'Cherry-sized mass } \\
\text { in fourth ventricle' }\end{array}$ \\
\hline nann 1956 & F 55 & 17 years & ++ & + & -1 & + & + & None found & $\begin{array}{l}\text { ? Severe closed } \\
\text { head injury }\end{array}$ \\
\hline nermeyer & $\leftarrow$ & - - - - & $-1-1$ & Not describ & ed - & -1 & $-\cdots-\rightarrow$ & + & $\begin{array}{l}\text { Aneurysm of } \\
\text { vertebral artery }\end{array}$ \\
\hline $\begin{array}{l}\text { in and } \\
\text { esle } 1957\end{array}$ & F 47 & 10 years & ++ & - & + & + & + & $\begin{array}{l}\text { Suspected, not } \\
\text { proved }\end{array}$ & Not discovered \\
\hline nthal & M 67 & $\begin{array}{l}\text { Not } \\
\text { known }\end{array}$ & + & + & $\begin{array}{l}\text { Not } \\
\text { known }\end{array}$ & - & + & - & Not found \\
\hline nthal & M 27 & $\begin{array}{l}\text { Not } \\
\text { known }\end{array}$ & $\begin{array}{l}\text { Because of } \\
\text { neoplasm, } \\
\text { could not } b\end{array}$ & $\begin{array}{l}\text { f widesprea } \\
\text { signs and } \\
\text { be properly }\end{array}$ & $\begin{array}{l}\text { d disseminat } \\
\text { ymptoms d } \\
\text { assessed }\end{array}$ & $\begin{array}{l}\text { tion of the c } \\
\text { ue to haemo }\end{array}$ & $\begin{array}{l}\text { causal } \\
\text { osiderosis }\end{array}$ & ++ & $\begin{array}{l}\text { Oligodendroglioma, } \\
\text { subarachnoid and } \\
\text { intraventricular } \\
\text { spread }\end{array}$ \\
\hline $\begin{array}{l}\text { ee, van } \\
\text { r, Morotta, } \\
\text { Olszewski }\end{array}$ & M 52 & $\begin{array}{l}10 \\
\text { months }\end{array}$ & - & + & - & $\begin{array}{l}+ \\
\text { (? due to } \\
\text { tumour) }\end{array}$ & - & $+t$ & $\begin{array}{l}\text { Ependymoma of } \\
\text { filum terminale }\end{array}$ \\
\hline & M 59 & 10 years & + & + & + & $\begin{array}{l}\text { Not } \\
\text { known }\end{array}$ & + & ++ & $\begin{array}{l}\text { Intracranial } \\
\text { angioma }\end{array}$ \\
\hline $\begin{array}{l}\text { inson and } \\
\text { on } 1964\end{array}$ & F 16 & 2 years & + & + & + & $\stackrel{+}{\text { Terminal }}$ & + & ++ & $\begin{array}{l}\text { Ependymoma of } \\
\text { lateral ventricle }\end{array}$ \\
\hline
\end{tabular}

Other Features

Positive C.S.F. Wassermann reaction, fixed pupils, absent reflexes

Absent knee jerks, sluggish pupils

Alcoholism

Diabetes mellitus, loss of position sense in legs; cirrhosis of liver Pyelonephritis, emphysema

subarachnoid and

(I.Q. 67). Her recent memory was severely impaired, there was marked fluctuation in her performance, and some of the test results suggested recent organic deterioration. Neck stiffness increased and the patient was now developing a progressive bilateral deafness of perceptive type. There was moderate symmetrical cerebellar ataxia of the arms and legs, but the tendon reflexes were active and equal, the plantar responses flexor. A lumbar puncture on 12 August gave fluid under pressure of $120 \mathrm{~mm}$. cerebrospinal fluid; the fluid was uniformly and deeply bloodstained. The packed cell volume in the fluid was $8 \%$ and the protein content of the deeply xanthochromic supernatant fluid was $5.0 \mathrm{~g}$. per $100 \mathrm{ml}$. An E.E.G. was more abnormal than the previous recording; it was now somewhat asymmetrical, showing more slow activity on the left side and particularly in the left temporal region, but no clear-cut focal abnormality was demonstrated. Ventriculography was performed by Mr. J. Hankinson on 14 August 1959. The intracranial tension was increased; the lateral ventricles were encountered at a depth of $5 \mathrm{~cm}$. The cerebrospinal fluid was deeply bloodstained with a mixture of fresh and recent blood. Air passed freely from the left to the right ventricle and a total of $40 \mathrm{ml}$. of cerebrospinal fluid was replaced with air. Radiographs demonstrated multiple filling defects in the lateral ventricles which were interpreted as being due to patchy coagulum and it was decided that no surgical treatment was possible. Shortly afterwards the patient developed retention of urine with overflow and bilateral extensor plantar responses. She gradually lapsed into coma and died on 3 September 1959.

PATHOLOGICAL FINDINGS At necropsy the body was that of a fully developed but very thin girl, $5 \mathrm{ft} .2 \mathrm{in}$. tall and weighing $44 \mathrm{~kg}$. ( $5 \mathrm{st} .4 \mathrm{lb}$.). There was no skin pigmentation. In the internal organs, apart from bronchopneumonia with abscess formation, there were no significant abnormalities outside the central nervous system. No pigment deposition or fibrosis was present in any of the general organs. The scalp and skull and dura mater 
were normal. In the subarachnoid space of the spinal cord and brain, particularly in the basal cisterns and over the pons and medulla and anterior third of the cerebellum, there was deep brown pigmentation with numerous adhesions and with brown staining of the outer layers of the cerebral cortex and spinal cord (Fig. 1). There was no fresh blood in the subarachnoid space. The basal vessels were embedded in adhesions and pigment but were all thin-walled and apparently normal. The origins of all the cranial nerves were pigmented, the pigmentation stopping abruptly at their exit from the subarachnoid space. Some nerves were only slightly pigmented, the fifth and sixth being only yellow at the origins, but the seventh and eighth were nigger brown, the latter for $7-8 \mathrm{~mm}$. and the pigmentation extended for $2-3 \mathrm{~mm}$. into the brain substance. The olfactory bulbs and the optic nerves within the skull were deep brown in colour. In the latter pigmentation extended to the posterior surface of the bulb but gradually diminished from the optic foramen peripherally. The origins of all the spinal nerves were deeply pigmented. Arachnoid fibrosis, which was marked at the base of the brain, had apparently obliterated the foramina of Lushka but not the foramen of Magendie.

There was considerable dilatation of both lateral ventricles and intense brown pigmentation of a $1 \mathrm{~mm}$. layer of subependymal tissue in all the ventricles. Multiple deep brown, ependymal granulations were present throughout all the ventricles and the left posterior horn was filled by a solid, vascular, granular tumour (Fig. 2). Two small deposits of tumour were visible in the anterior end of the left lateral ventricle, and a further deposit, $5 \mathrm{~mm}$. across, lay in the hypothalamus at the level of the tuber cinereum. Pigmentation was approximately $\frac{1}{2} \mathrm{~mm}$. deep over most parts of the cortex, $1 \mathrm{~mm}$. deep beneath the ependyma, $2-3 \mathrm{~mm}$. deep over the periphery of the pons, cerebral peduncles, the quadrigeminal bodies, and the medulla and the whole of the cord (Figs. 3 and 8). The entire thickness of the hypothalamus was pigmented. Pigmentation of the cervical cord left only a central unpigmented zone $4 \mathrm{~mm}$. across and the thoracic and lumbar cord showed an even smaller central zone of unpigmented tissue. The anterior third of the cerebellum was pigmented to a depth of $1 \mathrm{~cm}$., with visible shrinkage and disorganization of folia, particularly those of the vermis and of the structures in the roof of the upper end of the fourth ventricle. The central lobule and flocculus were not identifiable, being reduced to a deeply pigmented mass of honeycombed glial tissue.

The tumour in the lateral ventricle was a papillary type of ependymoma with a vascular stroma which included many thin-walled blood vessels, some of which were thrombosed. Within the tumour itself there was very little pigment; it was present in the interstitial tissue, but not within the tumour cells. The granular appearance of the ventricles was due to subependymal gliosis, with much pigment in macrophages and encrusting astrocytes. Such granulations were present throughout all the ventricular system, in the aqueduct and in the floor and roof of the fourth ventricle (Figs. 2 and 3). The ependymal cells contained either no pigment or only a few minute particles, the pigment being in the subependymal tissues. The choroid plexuses were deeply pigmented.
The pigment was almost entirely iron-containing, 으 giving a positive Perls's reaction. In unstained sections a $Z$ large quantity of pigment occurred as yellowish-brown or brown granular particles up to 4 or $5 \mu$ in diameter, $\bar{\delta}$ all apparently within macrophages. Fine pigment granules were present within macrophages in the pia arachnoide but some lay free and a little was present within fibro- $\square$ blasts. Very fine particles of iron-positive pigment, approximately $1 \mu$ in size, were present within the cyto- $\frac{\rho}{-}$ plasm of numerous hypertrophied astrocytes and in some macrophages. In astrocytes these particles were most. numerous at the base of the astrocytic processes, and $\vec{\Rightarrow}$ similar particles were seen in the adventitia and outer $\stackrel{5}{\rightarrow}$ media of blood vessels in the pia arachnoid and in theo periphery of round, hyaline bodies which formed a들 prominent feature of the histological preparations (Figs. $\overline{\bar{s}}$ 4 and 5). Some non-granular iron-positive material was $\overparen{\nabla}$ present within these hyaline bodies and macrophages. In $\mathrm{\varrho}$ iron-stained preparations almost no unstained pigmentes apart from a little lipochrome within an occasional $\vec{\circ}$ neurone could be identified. The pigment was removed ${ }_{-}^{\circ}$ from sections by treatment with $5 \%$ oxalic acid. It is con- $\vec{\omega}$ cluded, therefore, that almost all of the pigment depositedo in the central nervous system in this case was haemosiderin. Attempts to identify other pigments were almosto completely unsuccessful. A very occasional macrophage in the spinal cord and cerebellar cortex contained sudano-philic material and a very occasional neurone a smail quantity of lipofuscin. Haematoidin (bilirubin), calcium, and melanin were not found. The pigment will, therefoß, $\mathrm{O}$ from now on be called haemosiderin.

The hyaline bodies, previously mentioned, were pres in both neuronal and non-neuronal areas and in sonec parts of the outer cortex were very numerous (Figs. 4 a gd 5). They stained with differing degrees of eosinophilia and varied in size from 15 to $50 \mu$; they were oval or roux $\vec{c}, \overrightarrow{0}$ and usually well defined, appearing to have a limiting membrane. In many, fine particles of haemosiderin were: present, particularly in the periphery, and all gave a posi-o tive reaction for haemosiderin, though the intensity varied from a faint to a very strong reaction. The larger bodies $\bar{\partial}$ contained no nucleus, but an occasional small body hado a minute flattened peripheral nucleus. They contained no요 demonstrable lipid, showed no metachromasia with toluidine blue but were slightly metachromatic witho methyl violet, only faintly positive with periodic-acid 3 Schiff reagent, and were negative with carbol fuchsin or in attempts to stain by Schmorl's method. They showedo only a faint affinity for silver. It appears likely that the majority are degenerating macrophages since occasionally small groups of them were found in perivascular spaces. Although very numerous in this condition and in some 3 of the previous cases reported, identical bodies ate occasionally found in old haemorrhagic infarcts and $\varrho$ presumably result from bleeding and release of breakdown products of red cells in the central nervous system.

In all the pigmented areas there was macrophage reaction, marked astrocytic proliferation, and in someo places severe gliosis. In some areas there was actual necrosis and wherever pigmentation was heavy, damage $\mathrm{O}$ to neurones, myelin sheaths, and neurofibrils was present. In many areas marked endothelial swelling in smallo 


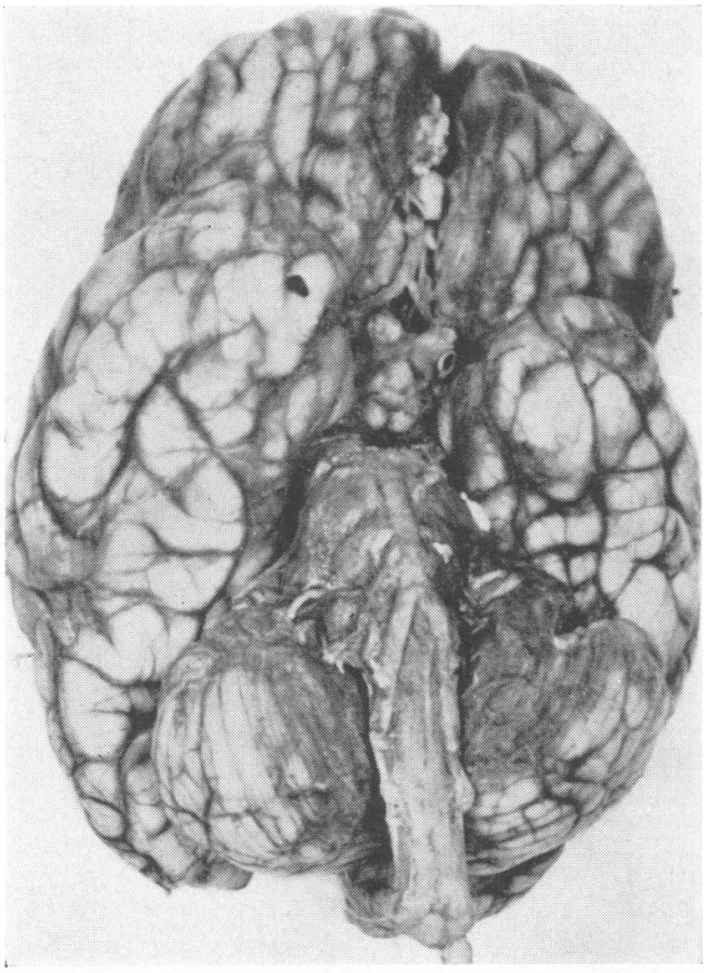

FIG. 1

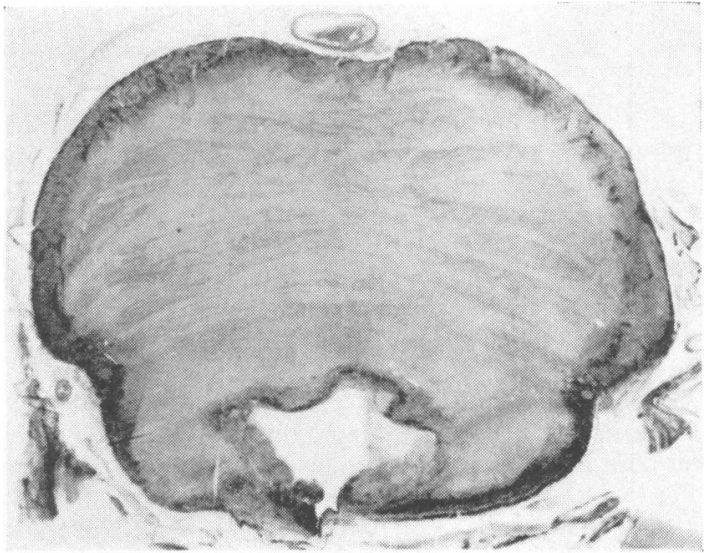

FIG. 3

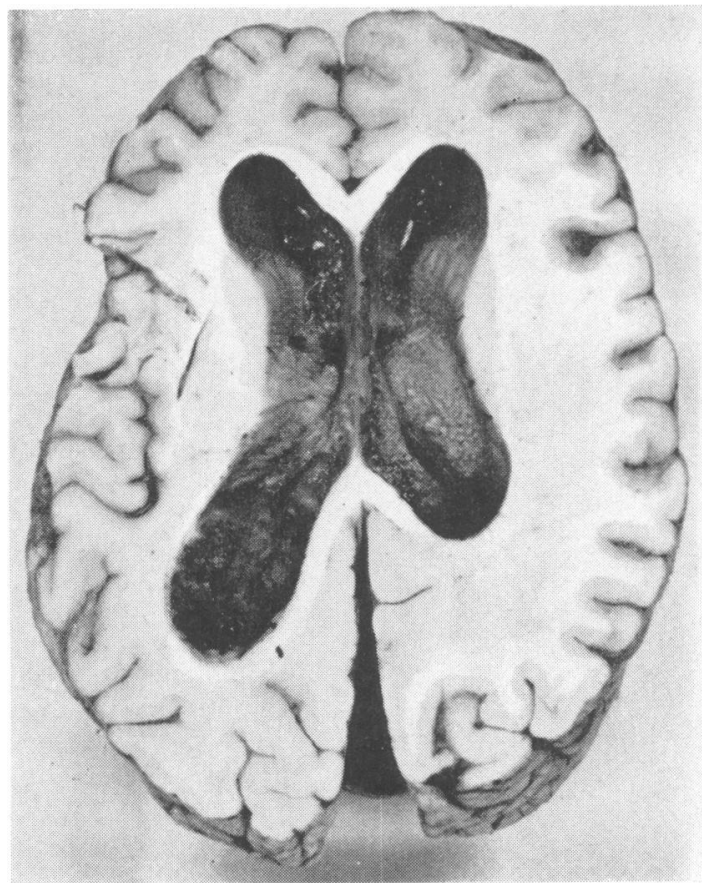

FIG. 2

FIG. 1. Pigmentation and arachnoid thickening is particularly prominent over the pons, medulla, and anterior third of the cerebellar hemispheres. The bifurcation of the basilar artery is hidden by pigment which has been removed from the interpeduncular cistern.

FIG. 2. Horizontal brain section showing the ventricular dilatation, pigmented granular ependymitis, and the tumour filling the posterior horn of the left lateral ventricle.

FIG. 3. Peripheral haemosiderin deposition at the level of the rostral limit of the fourth ventricle. Note the subependymal pigmented granulations in the roof and floor of the fourth ventricle. Perls $\times 4$. 


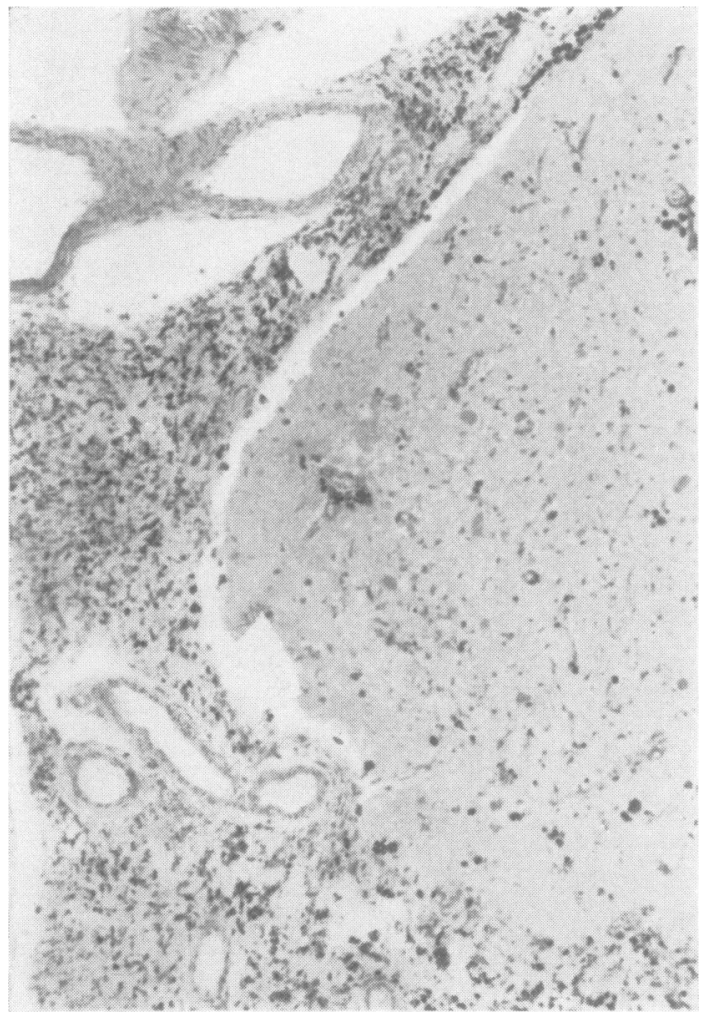

FIG. 4

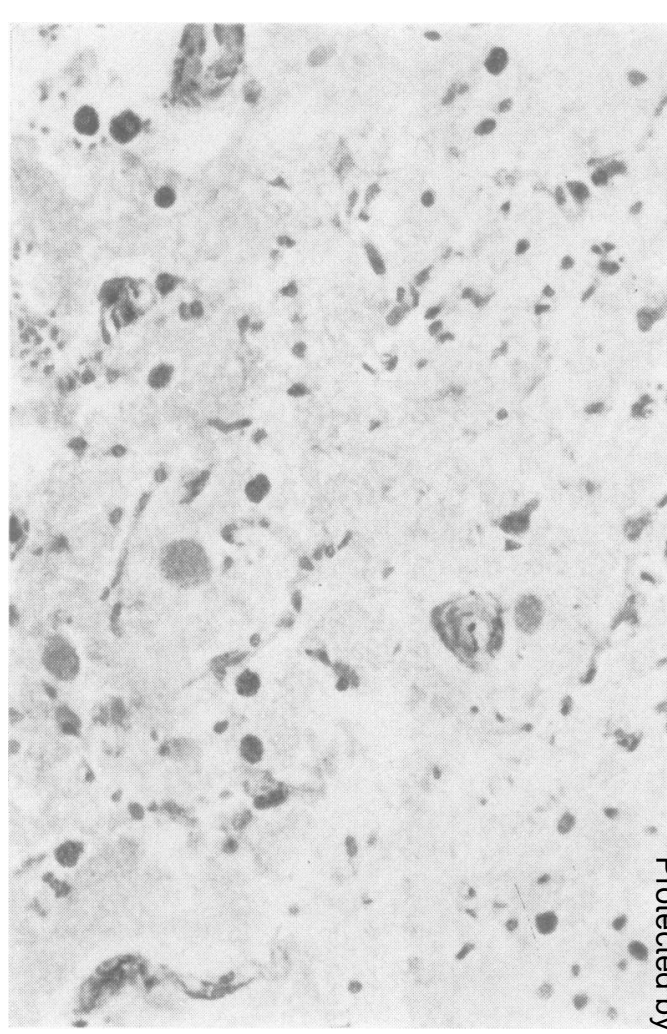

FIG. 5

FIG. 4. Apex of a frontal lobe convolution. The cellular, heavily pigmented pia arachnoid is adherent in one to the grossly disorganized superficial cortex. Haematoxylin and eosin $\times 58$.

FIG. 5. Higher-power view of the cortex of Fig. 4 showing a network of capillaries, heavily pigmented macrophagest and several hyaline bodies. A hyaline body and a neurone lie adjacent to an arteriole showing cellular subintimat hyperplasia. Haematoxylin and eosin $\times 220$.

arterioles was present, suggesting that some of the necrosis might be secondary to vascular occlusion.

In all areas of the cerebral cortex, an occasional macrophage and iron-encrusted astrocytes were present in the molecular layer. Pigmentation was heaviest over the apices of the convolutions, reaching the third layer of the cortex, and masses of pigmented macrophages were present around blood vessels, and in clumps and singly in the cortex, and throughout these areas there was marked astrocytic proliferation. In such areas there was severe loss of neurones (Figs. 4 and 5). Occasional shrunken or very pale-staining neurones could be found in the affected areas but in no identifiable neurone could iron pigment be demonstrated. Similar appearances were present in all exposed neuronal areas of the brain, such as the quadrigeminal bodies, and the pulvinar of the thalamus and the hypothalamus.

In the cerebellum more intense destruction had occurred, the midline roof structures in the rostral end of the fourth ventricule being reduced to pigmented glial scars, as were many of the collapsed folia (Figs. 6 and 7).
The incompletely destroyed folia had a characterist appearance; pigmentation, not necessarily heavy, wi limited to the apex of the folium where neuronal destrue tion was out of proportion to the degree of pigmentatios and resulted in marked thinning and collapse of the molecular layer with complete loss of the Purkinje cell Usually the cap of granular cells was also destroyed, but a thick layer of proliferated Bergmann astrocytes: remained, their processes encrusted with haemosideri

The periphery of the spinal cord was heavily pigmented haemosiderin being within macrophages and astrocyte but pigment was particularly heavy in the anterior horn. (Fig. 8), though the neurones appeared to be entire normal. The pigmented periphery of the cord showed partial demyelinization with numerous beaded ang swollen myelin sheaths and loss and fragmentation of neurofibrils.

Large clumps of macrophages and some astrocytês were present at the points of exit of cranial nerves and at the origins of ventral and dorsal nerve roots in the cordo The exit zones of the third and fourth nerves were on 


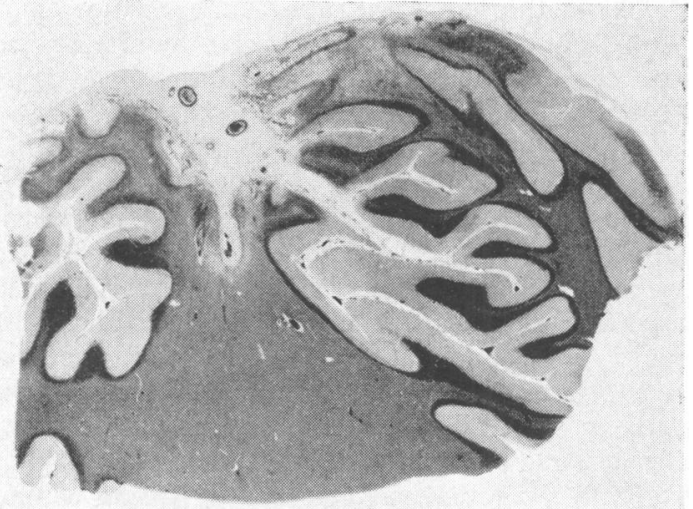

FIG. 6

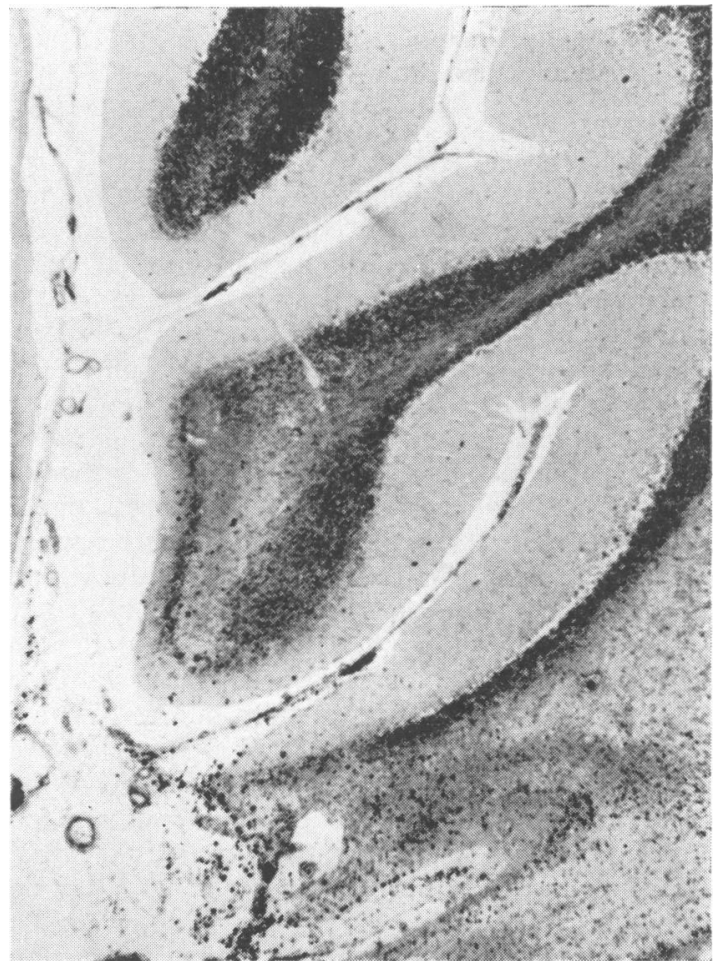

FIG. 7

FIG. 6. Destruction of the cerebellar hemisphere. Normal folia with heavily stained zones of granule cells lie deep to the eroded surface, where the outline of destroyed folia and the characteristic loss of granule cells at the apex of partly affected folia are visible. Haematoxylin and eosin $\times 5$.

FIG. 7. Varying destruction of cerebellar folia. In the central folium, the solid mass of granule cells which form the apex of a normal folium (at the top) has disappeared; the outline of the folium is altered from the normal clubshaped, to a flattened, mushroom-shaped top; the remaining cap of cells is hypertrophied Bergmann astrocytes. The thin, acellular molecular layer is just visible. The folium at the bottom has been completely destroyed. Haematoxylin and eosin $\times 50$.

FIG. 8. Perls's reaction on a section of the thoracic cord showing the heavy peripheral pigmentation, the small central unpigmented zone, and the heavily pigmented anterior horns. $\times 10$. 
slightly involved, but the second and eighth showed extremely heavy deposits of iron with considerable myelin loss, and iron deposition and astrocytic proliferation extended into the superficial areas of the dorsal and ventral cochlear nuclei. The optic nerves showed little loss of myelin or nerve fibres.

\section{DISCUSSION}

The symptoms and the physical signs in this case clearly resulted from the combined effects of the tumour and the haemosiderosis. Repeated small haemorrhages were presumably responsible for the recurrent severe headaches. Subsequently hydrocephalus, progressive dementia, and chronic subarachnoid bleeding brought to mind the possibility of an intraventricular tumour such as a choroid plexus papilloma, but the findings on ventriculography were inconclusive. The haemosiderosis of the central nervous system was almost certainly responsible for the cerebellar ataxia, the nerve deafness, and for much of the mental deterioration. This latter could be accounted for by the widespread though relatively superficial cortical destruction, but the associated hydrocephalus, possibly due to obstruction of the fourth ventricular foramina, could have been a contributory factor. The involvement of the eighth nerve at its origin and of the peripheral parts of the cochlear nuclei presumably caused the nerve deafness and the severe cerebellar destruction accounted for the cerebellar symptoms and signs.

In the case of Neumann (1948) marked destruction of anterior horn cells had apparently occurred as a result of the haemosiderin deposition. In that case, however, the illness was protracted, lasting more than 12 years. We observed marked pigmentation of the anterior horns at necropsy in our case, but signs of lower motor neurone weakness were not detected during life and there was no neuronal degeneration, though the latter change might have developed had the illness lasted longer. In the case we have described the partial demyelination and fibre damage in the periphery of the cord could well have given rise to sensory disturbances, e.g., loss of vibration and position sense in the legs, but the patient became so demented that accurate sensory testing was not possible. However, signs of pyramidal tract dysfunction only appeared as a terminal event.

The clinical findings in the 12 cases reported to date, including our case, may therefore be summarized by saying that eight showed bilateral nerve deafness, seven bilateral cerebellar ataxia, eight had evidence of bilarteal pyramidal tract disease, four retention of urine with overflow, four absent reflexes or impaired vibration sense in the legs, and at least seven showed progressive dementia in the terminal stages. Several of these features may have been present in the remaining cases but were not commented upon specifically in the case reports or else they were obscured by other neurological finding Turning to the pathological findings, all cases showee the characteristic brown staining of the meninges an of peripheral areas of the central nervous systemp usually with a striking degree of cerebellar degenera tion and atrophy. In seven there was definite. evidence of subarachnoid bleeding and in three it was suspected; only in two was there no evidence of meningeal haemorrhage. In one case the haemo rhage was due to an intracranial aneurysm, in twe to the presence of an ependymoma (of the filurf terminale and of the left lateral ventricle respectively). in one to a cerebral vascular malformation, in on to carcinomatosis of the meninges, and in one to ap oligodendroglioma. In the remaining cases no definite source of haemorrhage was identified (Table I). $\overrightarrow{0}$

There is no evidence in this case, as there has been none in the others in the literature, of generalized haemochromatosis and there is no reason to believe. that this is a form of that disease localized to the central nervous system. Cammermeyer (1947)i McDougal and Adams (1950), and Adams (1956) pointed out that in haemochromatosis depositionofo iron in the central nervous system is extrem if limited. The choroid plexuses are intensely pigg mented, but the deposition of iron pigment is confined otherwise to a few small foci in relation to ventricular system and to neuro-secretory areasso e.g., area postrema, pineal, and infundibulum. Pig mentation of the type described in the 12 cases have discussed has never been found in association with systemic haemochromatosis.

In cases of superficial haemosiderosis, by contrast, the iron deposition has been found in those areas bathed by circulating cerebrospinal fluid. Thus, the cerebral hemispheres, the cerebellum, and the outer layers of the cord and the brain-stem are involved $\stackrel{\mathbb{Q}}{2}$ The subependymal layers around the ventricles have $\vec{\delta}$ been found to be pigmented in a number of cases $\bar{F}$ in each of these a focus of intraventricular haemor rhage was present. In our case the haemorrhage was? clearly arising from the ependymoma in the laterat ventricle. The rarity of this condition in no sense detracts from the view that it is the result of frequentoor continuous haemorrhages occurring into the subarachnoid space or cerebral ventricles. Although subarachnoid bleeding is common, the cases in which it occurs repeatedly or over a long period of time musto be rare. It should also be noted that the changes in the pia arachnoid and in the superficial cortex closeo to a ruptured aneurysm are similar, though much less severe. Thus there is fibroblastic proliferation in the pia arachnoid with deposition of haemosiderin N in macrophages as well as in some fibroblasts and in 
the adventitia of blood vessels. Often there is considerable astrocytic proliferation in the outer layers of the cortex; the astrocytes are often aligned in rows and in some places their processes are encrusted with iron pigment. The curious large hyaline and haemosiderin-positive bodies found in our case and in a number of the reported instances are also to be found occasionally in relation to areas of old cerebral haemorrhage or haemorrhagic infarction. Furthermore, Iwanowski and Olszewski (1960) have studied the effects of multiple injections of heparinized blood, of haemolysed red cells, and of the iron preparation Imferon into the cisterna magna of dogs. They found that similar lesions in the cerebellar folia, as well as pia arachnoid pigmentation, incrustation of subpial astrocytes with iron-containing pigment, and, in some instances, foci of cortical necrosis occurred when multiple injections of blood were given. The evidence, therefore, that this condition is associated with haemorrhage into the subarachnoid space or ventricles seems to be conclusive. It cannot, however, be stated categorically that it is the deposition of haemosiderin itself which results in degeneration. This deposition may merely be the sign of haemorrhage rather than the explanation for necrosis. Indeed one piece of evidence strongly suggests that it is not haemosiderin itself which causes the necrosis; although neurones in many areas are apparently destroyed, and in the cerebellum necrosis of all tissues except the hypertrophied astrocytes and macrophages is to be found, little, if any, haemosiderin is found within neurones. In our case haemosiderin deposition was at its heaviest in the anterior horns of the spinal cord, yet the neurones themselves were intact and contained no haemosiderin. It thus seems probable that some other breakdown product of the blood and plasma liberated into the subarachnoid space is responsible for tissue damage rather than the haemosiderin itself and that the latter is merely an obvious and striking indication that repeated previous bleeding has occurred.

The relatively constant occurrence of the three main symptoms and signs of this condition, namely, nerve deafness, cerebellar ataxia, and dementia, shows that the eighth nerves and perhaps the peripheral parts of the cochlear nuclei constantly suffer, as do the cerebellum and the superficial layers of the cerebral cortex. It is, however, clear that other areas, particularly the anterior horns, roots, and long tracts in the spinal cord, may also be severely affected and may give rise to some of the predominant symptoms. Thus the impairment of position sense and of vibration sense in the legs reported in the case of Garcin and Lapresle (1957) would presumably be explained by degeneration of myelin and axons in the peripheral parts of the cord, and absent lower limb reflexes could be accounted for by either root or cord involvement. The bladder disturbances seen in our patient and reported in a number of those previously described probably result from involvement of the sacral segments of the cord or sacral roots. The bilateral pyramidal tract signs present in the majority of the cases can be explained either by the involvement of the pyramids within the medulla or by degeneration of the peripheral parts of descending tracts in the spinal cord. In our case demyelination was slight in these areas and signs of pyramidal tract dysfunction were only found terminally.

\section{SUMMARY}

The case is reported of a 16-year-old girl who gave a two-year history of recurrent headaches and of a recurrent right-sided visual field defect. Later she developed minor epileptic seizures, nerve deafness, dementia, cerebellar ataxia, urinary retention with overflow, and finally signs of bilateral pyramidal tract dysfunction. The cerebrospinal fluid was deeply blood-stained. At necropsy a vascular ependymoma of the left lateral ventricle was discovered and there was widespread staining of the meninges and of superficial and periventricular areas of the cerebral hemispheres, cerebellum, brain-stem, and spinal cord with haemosiderin. In the deeply-stained areas there was usually widespread degeneration of neurones and of glial cells; superficial demyelination was observed not only in the brain-stem and spinal cord but also in cranial nerves and nerve roots.

This is the twelfth case of haemosiderosis of the central nervous system to be reported in the world literature. The clinical and pathological findings in these 12 cases are discussed. The predominant clinical features of the illness are nerve deafness, dementia and cerebellar ataxia, with eventually, retention of urine with overflow and other signs of spinal cord disease. Reasons are given for concluding that the syndrome results either from repeated small haemorrhages or from continuous bleeding within the subarachnoid space over a prolonged period of time.

We are grateful to E. Manns, A. Willis, and Miss R. Allen for their help.

\section{REFERENCES}

Adams, R. D. (1956). J. Neuropath. exp. Neurol., 15, 215.

Cammermeyer, J. (1947). Ibid., 6, 111.

Garcin, R., and Lapresle, J. (1957). Rev. neurol., 97, 417.

Iwanowski, L., and Olszewski, J. (1960). J. Neuropath. exp. Neurol., $19,433$.

Lewey, F. H., and Govons, S. R. (1942). Ibid., 1, 129.

McDougal, D. B., and Adams, R. D. (1950). Ibid., 9, 117.

McGee, D. A., van Patter, H. J., Morotta, J., and Olszewski, J. (1962). Neurology (Minneap.), 12, 108.

Neumann, M. A. (1948). J. Neuropath. exp. Neurol., 7, 19.

(1956). Ibid., 15, 214.

Noetzel, H. (1940). Arch. Psychiat. Nervenkr., 111, 129.

Rosenthal, P. (1958). Dtsch. Nervenheilk., 178, 431. 